\title{
Metaphors in the First Stanza of Ode to the West Wind:
}

\section{A Cognitive Linguistic Approach}

\author{
Donghong Zhan \\ School of English and International Studies, Beijing Foreign Studies University \\ 2 Xi San Huan North Road, Beijing 100089, China \\ Tel: 86-10-8881-1139 E-mail: donnazhan@yahoo.com
}

\begin{abstract}
Metaphor is ubiquitous and it is a way of conceptualizing human experiences. But the metaphors used in poetry are not the same as those employed in daily life although the metaphors maneuvered in poems are often based on those used in daily life. The metaphors employed in poems are always extended, elaborated and compressed into one poem by poets. And this is what makes poetic metaphors different from common metaphors. Ode to the West Wind is one of the best lyric and political poems of the English romantic poet Percy Bysshe Shelley. And the metaphors maneuvered in this poem are a good evidence of this point.
\end{abstract}

Keywords: Metaphor, Image metaphor, Source domain, Target domain, Mapping

\section{Introduction}

What is metaphor? In order to answer this question we should first know that metaphor in different fields means different things. Metaphor in literature and rhetoric is not the same as metaphor in psychotherapy, or metaphor in computer science. Therefore the author would like to clarify at the beginning of this article that the metaphor that is going to be discussed is to be understood from a cognitive perspective. Metaphor in cognitive linguistics is 'the use of language that designates one thing to designate another in order to characterize the latter in terms of the former' (Wilson \& Keil, 2000). According to this definition, language is just a tool to represent conception and the function of metaphor is to designate things. In line with this definition, conceptual metaphor refers to the understanding of one idea, or conceptual domain in terms of another (Wikipedia, 2008). The characteristics of metaphor in cognitive linguistics include: 1) Metaphor is ubiquitous; 2) Metaphor is conceptual in nature; 3) Metaphor is systematic; 4) Metaphor is composed of two domains, a source domain and a target domain; 5) Metaphorical mappings are grounded in bodily experience (Lan, 2003, 31). In accordance with these characteristics, we can conclude that metaphors are not limited to novel creations of talented writers and thus not patents for literary works, e.g. poems. They are "part of the way members of a culture have of conceptualizing their experience' (Lakoff \& Turner, 1989).

Metaphors and poems are inextricable, without metaphor, poems and all the other literary works will suffer an eclipse. In line with Lakoff \& Turner (1989), all the metaphors used in poetry are basic ones; nevertheless poets extend, compose and compress the basic conventional metaphors in order to satisfy their needs. In order to get a clear view of this point, Lakoff \& Turner analyzed the poem The Jasmine Lightness of the Moon: To a Solitary Disciple composed by William Carlos Williams in that book. Trying to verify the findings of Lakoff and Turner, the present article is going to examine Shelley's Ode to the West Wind.

Ode to the West Wind can be comprehended as metaphorical on two levels. First, it is a lyric poem which speaks highly of one of the elements of nature - the wind. In the process of acclaiming west wind, Shelley employed a large number of metaphors. Second, the poem as a whole can be given a metaphorical interpretation and comprehended as a political poem. It can be understood as an ode to freedom and revolution through complimenting the west wind. The present study discusses the use of metaphors in the poet's compliment of the west wind first and such an analysis is treated as a first level analysis of the poem. On the basis of this analysis, the author will elaborate the metaphorical understanding of the poem.

There are many uses of metaphors in this poem. Due to the limitation of space, the author is going to discuss just the metaphors maneuvered in the first stanza of this poem. Nonetheless the author thinks that it is enough to show the subtle 
and exquisite effects achieved by using metaphors in the whole poem by discussing one stanza of it. There are two reasons. When it comes to the quantity, one stanza stands for one fifth of the poem; when it comes to the style, the metaphorical style used in the first stanza is in consistency with the remaining four other stanzas so that the combination of all the five stanzas can make an excellent whole. The first stanza of Ode to the West Wind listed below is an excerpt from Reiman \& Powers (1977).

1). O wild West Wind, thou breath of Autumn's being

2). Thou, from whose unseen presence the leaves dead

3). Are driven, like ghosts from an enchanter fleeing,

4). Yellow, and black, and pale, and hectic red,

5). Pestilence-stricken multitudes: O Thou,

6). Who chariotest to their dark wintry bed

7). The winged seeds, where they lie cold and low,

8). Each like a corpse within its grave, until

9). Thine azure sister of the Spring shall blow

10). Her clarion o'er the dreaming earth, and fill

11). (Driving sweet buds like flocks to feed in air)

12). With living hues and odors plain and hill:

13). Wild Spirit, which art moving everywhere;

14). Destroyer and Preserver; hear, oh hear!

\section{Analysis of the first stanza of Ode to the West Wind}

Analysis on the first level

'O wild West Wind, thou breath of Autumn's being', in this line the poet first considers the west wind as a human being who can hear and comprehend so that he begins this line, actually this poem with a vocative ' $O$ wild West Wind'. This is one case of personification. Nevertheless the readers seldom deem this as an example of personification as it is so conventional and automatic that it becomes unconscious and unmarked. This is also evidence that poetic metaphors are based on conventional metaphors. What's more, the personification of west wind is made more explicit by using the second person pronoun 'thou'. Then this personification is followed by another one: the autumn is regarded as a human being who can breathe, and the west wind is the breath of autumn. Therefore in the same line there are three metaphors compressed: THE WILD WEST WIND IS A HUMAN BEING, THE AUTUMN IS A HUMAN BEING and THE WILD WEST WIND IS THE BREATH OF A HUMAN BEING. The frequent manipulation of personification also proves the anthropocentric view when people perceive the world. Actually the employment of personification is carried on in the second line where the poet begins with a vocative 'Thou' which co-refers to the west wind. Following the vocative 'thou', 'from whose unseen presence the leaves dead/ Are driven,' the poet regards the west wind as a human being who can be present or absent and can drive away the autumnal leaves. In the second line, when the poet depicts the autumnal leaves with the adjective 'dead', the leaves are also understood as human beings who experience the process of birth, youth, maturity, decrepitude, illness and death. The metaphor used here is LEAVES ARE HUMAN BEINGS. This metaphor is the extension of PLANTS ARE ANIMATE BEINGS. Most of the leaves in late autumn are in the dead state. When the mighty west wind blows, the dead leaves fall off the trees and flutter in a confusion. In order to depict the scene clearly, the poet employs a simile: 'like ghosts from an enchanter fleeing'. Through this simile, the strength and formidableness of the west wind as a destroyer and the fear, weakness and helplessness of the leaves when they face the strong wind are vividly delineated. The metaphors used in the two lines 'Thou, from whose unseen presence the leaves dead/ Are driven, like ghosts from an enchanter fleeing,' are THE WILD WEST WIND IS A DESTROYER and THE DEAD LEAVES ARE THE VICTIMS. The two metaphors are the extensions of WIND IS A HUMAN BEING and LEAVES ARE HUMAN BEINGS.

There are also three image metaphors triggered in the tercet discussed. First the image of two interlocutors communicating is mapped onto the poet's soliloquy. The second image metaphor that is created is that the image of a human being's act of breathing forcefully is mapped onto the autumnal wind's mighty blows. The image of an 
enchanter's presence terrifying the ghosts is mapped onto the image of the powerful west wind blowing the dead leaves off the branches and flutter in confusion.

In the fourth line, the poet further depicts the colors of the dead leaves. They are 'Yellow, and black, and pale, and hectic red' which are colors arousing people's negative feelings. In specificity, when the adjective 'pale' is employed to describe a person's complexion, the person in consideration is often shocked, frightened or in ill health (Sinclair, 2000); when 'hectic' is used to depict a human being, the person depicted more often than not suffers from a regular recurrent fever typically accompanying tuberculosis, with flushed cheeks and hot, dry skin (Mckean, 2005). Hence the description of colors by employing 'pale' and 'hectic' can be regarded as both a metonymic and a metaphorical use. It is metonymic because 'pale' and 'hectic' are often used to describe a person's complexion. When the complexion or the face of a person stands for the person possessing the face or complexion, the usage becomes metonymic. It is metaphorical because the vocabularies used for depicting a human being are used for describing the leaves. The metaphor used here is LEAVES ARE HUMAN BEINGS. Like human beings, the leaves in the deep autumn are seriously ill - they are 'Pestilence-stricken'. According to Sinclair (2000), the noun 'pestilence' refers to 'a disease that spreads quickly and kills large numbers of people'. Hence only human beings can be pestilence-stricken; as a result, this is an employment of personification. The personification is made more straightforward by using the word 'multitude' which means 'a very large number of people' (Sinclair, 2000). Then the poet further delineates the situation of the fallen leaves. Shelley regards the west wind as a charioteer and it transports the leaves to their ultimate home - the grave, i.e. the earth. In line six, 'chariot' is used as a verb and it symbolizes the inexorable force - the death. In the same line the 'DEATH IS A JOURNEY' metaphor is employed. Here the grave of the leaves is referred to as 'dark wintry bed' as the grave is always dark and as cold as the temperature in winter. The metaphor GRAVE IS BED is employed by the poet and it is the extension of the DEATH IS SLEEP metaphor.

There are five image-metaphors triggered in this tercet. First, the complexion of serious patients is mapped onto the colors of withered, frost-stricken leaves. Second, the situation of the pestilence-stricken people is mapped onto that of the late-autumnal leaves. Third, the bed of a human being is mapped onto the grave of the leaves. Fourth, the state of sleep is mapped onto the state of death. Last, the temperature in winter is mapped onto the temperature in the leaves' grave - the earth.

The relentless west wind not only sheds the leaves from the trees and sends them to their wintry bed - the earth, but also takes the seeds off the plants and carries them to the earth too. 'The winged seeds, where they lie cold and low/Each like a corpse within its grave' delineates the situation of seeds in the earth after the west wind makes the sweep. Here the seeds are depicted as something animate with wings like angels or birds. This is another extension of the metaphor PLANTS ARE ANIMATE BEINGS. But now they stay in the earth inactive like corpses lying in graves which are cold and low. Nevertheless the inert situation of the seeds buried in the soil will change when the breeze of spring blows, in other words, when spring comes. In the poem, the spring wind is depicted with personification: it is regarded as the sister of autumnal west wind - 'Thine azure sister of spring'. This is another evidence of the metaphor: WIND IS A HUMAN BEING. By employing this metaphor the autumnal wind and the spring wind can be considered as sisters. As is the norm in sunny spring, the color of the sky is always in bright blue, 'azure' is used here metaphorically to modify wind.

In this tercet, six image-metaphors are sparked off. First, the ability and image of the winged animates like angels and birds are mapped onto those of the seeds when the mighty wind blows. Second, the act of animates lying down is mapped onto that of seeds stay still in the earth. Third, the condition of graves is mapped onto that of the place where the seeds are: deep in the earth, cold and low. Fourth, the vision of the corpses in the graves is mapped onto that of the seeds in the earth: 'Each like a corpse within its grave'. Fifth, the relationship between human beings, exactly speaking, 'sisters' here, is mapped onto the relationship between the autumnal wind and the spring wind. Sixth, the pleasantness of the azure sky is mapped onto the sweetness of the spring wind.

In 'Her clarion over the dreaming earth', the spring thunder is understood as the clarion of spring wind. As a clarion is a kind of trumpet and generally speaking, human beings are always the master of it, hence this line carries on the metaphor employed in the ninth line WIND IS A HUMAN BEING. Combined with this metaphor is another: EARTH IS A HUMAN BEING. In line with this metaphor, the earth can sleep and wake up as a person. As when a person plays a clarion he or she will make some sound and if there is someone sleeping nearby, he or she will undoubtedly wake up. In this line there is also the use of metonymy, as when a clarion is kept untouched it won't make any noise. According to the source domain, when the spring thunder happens, the sleeping earth will be awakened. In the following line, the 'sweet buds' is also a metonymical use as sweet buds stand for the whole of flowers. Then the poet compares the spring thunder precipitating the flowers into full blossom with a shepherd driving flocks of sheep with a simile 'Driving sweet buds like flocks to feed in air'. Just like a shepherd drives flocks of sheep on the prairie, lets the sheep graze and gets them nourished, the spring thunder spurs the flowers to bloom and gets the blooms nourished in the air. Now let's connect line ten with line twelve, then we get that 'Her clarion ... fill with living hues and odors plain and hill'. 
According to our common sense, the action of filling requires something animate to perform the role of an agent, e.g. a human being. Thus this is another metaphor: SPRING THUNDER IS A HUMAN BEING.

The image metaphors provoked in this tercet are: first, the sound of blowing a clarion is mapped onto that of the spring thunder; second, the image of a sleeping person is mapped onto that of the frozen earth; third, the event that blowing a clarion wakens the sleeping person is mapped onto the event that the spring thunder signals the coming of spring and consequently thaws the earth and sprouts, grows and blooms the seeds in it; fourth, the image of a shepherd driving and feeding his flocks of sheep on the grassland is mapped onto that of the spring thunder spurring the flowers in blossom and getting them nourished in the air; fifth, the visualization of a person fills an empty bottle with water is mapped onto that of the spring thunder stuffs the plain and hill with flowers.

In the thirteenth line of this stanza, the poet compares the Wild West wind to a 'Wild Spirit' which is moving everywhere; hence the metaphorical use WEST WIND IS WILD SPIRIT. The Wild West wind and the Wild Spirit share the similarity that both of them can go anywhere they want. Then the poet refers to the west wind as 'Destroyer and Preserver' because the west wind not only drives away the dead leaves but also brings the seeds to the soil so that the seeds can prepare for their new lives. As a matter of fact, the 'titles [Destroyer and Preserver] come directly from the titles of the Hindu gods Siva the Destroyer and Vishnu the Preserver' (Reiman \& Powers, 1977, p221, note 6). When the names of gods are used to refer to the wind, they undoubtedly become metaphorical. As the poet considers the west wind as a human being who can sense, he asks the west wind to 'hear' and end this stanza of the poem with an imperative 'hear, O hear!'

There are four image metaphors sparked off in those two lines. First, the vision of a wild spirit who is moving everywhere is mapped onto that of the west wind sweeping through the forest. Second, the image of the Destroyer Siva is mapped onto that of the west wind damaging the dead leaves. Third, the image of the Preserver Vishnu is mapped onto that of the west wind protecting and carrying the seeds into the earth so that the seeds can breed their new lives. Last, the act of listening by a human being is mapped onto that of west wind. Those are the analysis of the first stanza of the poem on the first level; the next section will be devoted to the elaboration of the same stanza with a metaphorical interpretation.

\section{Analysis at the second level}

Ode to the West Wind 'is considered as both a political poem and one of Shelley's best lyrics' (Gong \& Guo, 2007, $\mathrm{p} 154$, note 1). In other words, this poem can be considered not only as the poet's compliment to the west wind but also metaphorically as a way of the poet to express his emotion towards revolution through the delineation of the west wind. For this reason the west wind symbolizes the revolutionists. The dead leaves represent the outdated world and its tyrannical government. The seeds symbolize the conviction of the revolutionists and the newly-born force. 'Her clarion' - the spring thunder refers to the appeals of the revolutionists and progressives. The sleeping earth denotes the masses. The referral of the west wind as the Destroyer can be explained by the event that the revolutionists overthrow the outmoded society and its tyrannical government. The mentioning of the west wind as the Preserver can be expounded because the revolutionists preserve their own conviction and the newly-born force of the future progressive society.

There are eight image metaphors created in this stanza. First, the event that the west wind drives away the leaves is mapped onto the event that the revolutionists overthrow the tyrannical government. Second, the panic of the dead leaves confronting the blow of west wind maps onto the panic of the reactionaries and the tyrannical government when they face the revolutionists. Third, the event that the west wind drives away the leaves to their dark wintry bed maps onto the event that the revolutionists topple the reactionary government. Fourth, the event that the west wind preserves the seeds is mapped onto the event that the revolutionists protect and maintain the conviction and newly-born force of the future progressive society. Fifth, the event that the seeds lie in the earth in winter maps onto the event that the newly-born forces of the new society save and accumulate their power and await their opportunity. Sixth, the coming of spring maps onto the coming of the opportunity for the revolutionists to act. Seventh, the event that the spring thunder awakens the frozen earth maps onto the event that the revolutionists' appeal awakens the mind of the masses. Last but not least, 'Wild Spirit, which art moving everywhere' maps onto the spread of the revolutionary ideas.

\section{Conclusion}

This paper analyzes the metaphors employed in the first stanza of Ode to the West Wind at two levels adopting a cognitive linguistic approach. On the first level, this stanza is considered simply as a praise of the west wind as a destroyer and preserver; on the second level, the whole stanza is deemed as metaphorical with the west wind symbolizing the revolutionists. As Shelley is a Romantic poet, he employs a large number of metaphors in his poems so that the poems will be vivid, readable and forceful. The poem Ode to the West Wind is typical of his style which is brimming with metaphors. For this reason, this poem is a good example to show the way Shelley extends and compresses a large quantity of conventional metaphors in one poem to reach his aim. Through analyzing the first stanza of Ode to the West Wind, George Lakoff and Mark Turner's view that poetic metaphors are based on conventional ones 
and the poets extend, elaborate and compress the conventional metaphors is once again corroborated.

Nevertheless the depth and breadth of this research is quite restricted. Researchers can also do more research on the manipulation of metaphors in poetry, not only English poetry, but also Chinese poetry.

\section{References}

Chayes, I. (1964). "Ode to the west wind". In Reiman, D., \& Powers, S. (Ed.), Shelley's poetry and prose: authoritative texts criticism (pp.620-25). New York: W.W. Norton \&Company Inc., 1977.

Conceptual metaphor. (May 29, 2008.). [Online] Available: Wikipedia: http://en.wikipedia.org/wiki/Conceptual_metaphor (Retrieved June 23, 2008).

Gong, Y. \& Guo, H. (2007). An introduction to English literature. Beijing: Qinghua University Press: Beijing Jiaotong University Press, Pp151-156.

Lakoff, G.., \& Turner, M. (1989). More than cool reason. Chicago and London: The University of Chicago Press.

Lan, C. (2003). A Cognitive approach to spatial metaphors in English and Chinese. Beijing: Foreign Language Teaching and Research Press, P31.

Mckean, E. (Ed.). (2005). The New Oxford American Dictionary (2nd ed.). New York: Oxford University Press.

Reiman, D., \& Powers, S. (Ed.), (1977). Shelley's poetry and prose: authoritative texts criticism (p. 221). New York: W.W. Norton \&Company Inc..

Sinclair, J. (Ed.). (2000). Collins Cobuild English Dictionary (new ed.). Shanghai: Shanghai Foreign Language Education Press.

Wilson, R. \& Keil, F. (2000). The MIT Encyclopedia of the Cognitive Science. Shanghai: Shanghai Foreign Language Education Press. 